Valdir Ferreira, Eduardo Sérgio Marques Lázzaro, Arnaldo Almendros Mello

Secretaria Municipal de Saúde de São José do Rio Preto. Núcleo de Educação, Saúde e Comunicação.

Endereço: Av. Romeu Strazzi, 199, Jardim Sinibaldi, CEP 15034-010, São José do Rio Preto, SP, Brasil.

E-mail: marisacesarino@yahoo.com.br

A avaliação do Programa de Controle à Dengue mostrou que a coleta de criadouros potenciais era fator condicionante da ação dos Agentes de Saúde. Firmouse convênio com 50 carroceiros, em Associação, para realizar a coleta e destinação dos criadouros. Os carroceiros foram integrados ao trabalho dos Agentes após capacitação; o número e funções dos pontos de apoio foram ampliados; e foi implantada planilha de coleta. A experiência possibilitou o fortalecimento do papel dos Agentes como educadores em saúde ambiental; avançou no processo de inclusão social dos carroceiros e na melhoria da autoestima e identidade de ambos os atores. A auto-organização dos carroceiros em cooperativa resultou no cadastro dos animais, das carroças, dos mesmos como condutores e na proposta de implantação de "central de compras e disque carroça". O projeto evidenciou a relevância da co-gestão em saúde.

\title{
O Controle da Dengue com o Auxílio de Carroceiros
}

Marisa Bernardi Cesarino, Amena Alcântara Ferraz, 